$\xi_{p}$

\title{
Hybrid Search Approach for Retrieving Medical and Health Science Knowledge from Quran
}

\author{
Muhammad Afifi Mohamad Safee ${ }^{1}$, Madihah Mohd Saudi ${ }^{1,2 *}$, Sakinah A. Pitchay ${ }^{1,2}$, Farida Ridzuan ${ }^{1,2}$, \\ Nurlida Basir ${ }^{1,2}$, Kamarudin Saadan ${ }^{1}$, Fatin Nabila ${ }^{1}$ \\ ${ }^{I}$ Faculty of Science and Technology, Universiti Sains Islam Malaysia (USIM), Malaysia \\ ${ }^{2}$ CyberSecurity and Systems Research Unit, Islamic Science Institute (ISI), Universiti Sains Islam Malaysia (USIM), Malaysia \\ *Corresponding author E-mail: madihah@usim.edu.my
}

\begin{abstract}
Keyword-based technique has low accuracy and always leads to wrong information retrieved. Therefore, many researchers implement semantic search to overcome the above problems. Many researchers have built different Quran ontology in various domains to facilitate the knowledge representation in the Quran. Nevertheless, there are many domain concepts mentioned in the Quran which are not yet covered, especially for the Medical and Health Science domain. Hence, this research presents the development of ontology for the Medical and Health Science domain in the Quran and implementation of ontology-based search method to answer related queries in the Quran. The development of ontology adopts the ontology 101 approach which later evaluated by Quran experts. Furthermore, a hybrid search tool was developed that encompassed semantic-based and keyword based technique to answer a user query. The search tool was evaluated using the Recall and Precision measurements, which shows high accuracy in retrieving the Medical and Health Science knowledge in the Quran. For future work, this research can be used as a reference and basis to answer user queries, data integration with other applications or existing ontology can be further expanded.
\end{abstract}

Keywords: Information Retrieval; Medical and Health Science; Quran Ontology.

\section{Introduction}

Al-Quran is referred as one of the primary resource for Muslims. Muslims believe that the Al-Quran contains information related to science, prediction of future, law, and others. The information can be retrieved throughout the Al-Quran. Recently, there are more studies and research work related to Al-Quran and sciences [1]. In [2] in his research highlighted that search and retrieval of knowledge in Al-Quran sometimes lacks accuracy due to the nonimplementation of sophisticated and dynamic ways for retrieving knowledge or verses. Moreover, the present way of searching in Al-Quran is not based on knowledge classification. Hence, this shows that there is weakness in searching and retrieving the verses in Al-Quran [3].

Recently, there are two techniques for knowledge retrieval for AlQuran which are known as keyword-based and semantic based [4] The keyword-based technique finds possible word combination that is relevant to the keyword, while semantic-based technique finds similarity based on matching the contextual meaning of a keyword based on concept [5]. Semantic-based technique is defined as knowledge retrieval process that exploits domain knowledge, which is formalized by means of an ontology [6]. Ontology, which is the backbone for semantic-search technique has been considered as an adequate methodology to support a variety of activities such as knowledge retrieval, storage, sharing and dissemination [7]. Many studies have shown the effectiveness of ontology-based search engine over keyword based search engine [8]. Ontology uses concepts, such as classes and relationships between properties of classes, to search verses and establish the knowledge contained in the Quran [9]. The concept in the Quran is referred to as verses, which are defined by a hierarchy of division, chapter, and verse [10]. Previous studies such as [11, 2, 5] have emphasized that existing Al-Quran verses retrieval can be significantly retrieved by using an ontology-based approach.

The current approach increases the difficulty in obtaining accurate knowledge because the verses are retrieved not according to domain classification hierarchy. The results are difficult to sort and facilitate reader understanding [12]. However, this deficiency can be resolved by employing the ontological approach and by classifying Al-Quran verses according to themes that can be more easily understood by readers [2]. Themes classification, which is referred to as thematic approach, is a way of teaching and learning such that many areas of knowledge are integrated and connected within a theme. Therefore, it allows learning to be less fragmented and more natural [3].

Many of the existing works, including the study carried out in [2] are based on semantic search for related verses in Al-Quran, which do not give accurate results in retrieving knowledge when searching for the keywords as it does not use the theme concept. However, finding verses in Al-Quran through the keyword search and retrieving using ontology approach is much easier and straight forward.

Therefore, this paper presents the development of ontology for the Medical and Health Science domain in Al-Quran. For this ontology development, the concepts are manually extracted by experts from the Faculty of Quranic and Sunnah Studies (FPQS) and Faculty of Medicine and Health Sciences (FPSK), Universiti Sains Islam Malaysia (USIM). This research also developed a search tool to facilitate retrieval of Medical and Health Science knowledge extracted from the Quran. 
This paper is organized as follows: Section 2 presents related works. Section 3 presents the processes of the ontology methodology. Section 4 presents the findings and evaluation of the ontology modeling. Finally, Section 5 concludes the paper and discusses future work.

\section{Related Works}

In this section, we describe related works on Al-Quran search and retrieval approach, and the ontology-based research for Quran.

\subsection{Al-Quran Search and Retrieval Approach}

Currently, many Al-Quran search tool and applications have been developed for knowledge retrieval from it. Every tool has different capability depending on the focus area, and techniques [13]. Previously, there are two main approaches for knowledge retrieval from Al-Quran which are keyword-based and semantic-based techniques. The semantic-based technique is a concept-based search tool that retrieves results based on word meaning, or concept match, whereas the keyword-based technique returns results based on letters matching word(s) queries [14]

A study by [13] has classified several of Al-Quran searching approaches. The existing approach for text-based (keyword-based) can be referred in the existing work done by [15]. This research designs Optical Character Recognition (OCR) for recognition of the Arabic alphabet. It computes image-morphological features on input of word images. Moreover, a Chatbot has been created to search and to match based on the keyword to find relevant verses for Arabic web [16]. The Chatbot matches the important word from the search field and perform simple keyword based searching to find the relevant verses from Arabic web.

There are several deficiencies concern with the Quran verses retrieval using existing keyword search techniques. Among the known problems are, relevant verses are not retrieved and irrelevant verses are retrieved, or the sequences of retrieved verses are not in the correct hierarchy [11]. Additionally, the keyword-based techniques have limitation in understanding the meaning of input words and neglecting some theories of information retrieval [17]. Due to drawback from keyword-based techniques, the semanticbased techniques have been used by current researchers in facilitating verses retrieval from the Quran. The existing semanticbased techniques for the Quran includes ontology-based techniques that can be seen in [18] works. They applied the ontology semantic based approach to represent the Quran domain for searching [18]. This research creates ontology concept "nouns" from Al-Quran. The searching technique searches the concept(s) matching user query and returns the verses related to this concept They used dataset from Leeds University for evaluation. Another semantic-based approach is by using cross-language information retrieval (CLIR) technique. This approach can be seen in the work presented by [19-20]. The Quran concept is applied for disambiguating translation of the query. These works aim to improve dictionary-based query translation. Moreover, there are works which use the synonyms-set as described in [11]. This research exploits WordNet relationships in a relational database model. This model retrieves $80 \%$ more accuracy than existing keyword-based technique. Table 1 summarizes the above existing works.

\subsection{Ontology-based Research for Quran}

There are several studies which have been initiated on the topic of Quran ontology. Most of these studies have been developed in order to improve the efficiency of information retrieval and knowledge representation for the Quran.
Table 1: Comparison Study of Existing Al-Quran Searching Method/approach

\begin{tabular}{|c|c|c|}
\hline References & Approach & Method \\
\hline$[18]$ & Semantic-Based & Ontology-based approach \\
\hline$[11]$ & Semantic-Based & Synonym-set (Wordnet) \\
\hline$[19-20]$ & Semantic-Based & $\begin{array}{c}\text { Cross-language information retriev- } \\
\text { al (CLIR) }\end{array}$ \\
\hline$[15]$ & Keyword-Based & Morphological search \\
\hline$[16]$ & Keyword-Based & Pattern matching technique \\
\hline
\end{tabular}

These have facilitated the process of accessing Quran knowledge. However, most research has different aspects such as the domain coverage of the Al-Quran, language of the text used; original Arabic text or other translation, domain focused on, number of concepts and types covered, concept extraction method, relation types and verification method.

Based on the existing works listed in Table 2, most research focus on specific domains inside the Al-Quran, Nevertheless, there are still many domain concepts mentioned in the Quran which are not yet covered. Apart from that, due to essence of semantic technology that uses ontology to describe the meaning of data, there are needs for extensive research to explore other knowledge classification for Al-Quran, especially in the Medical and Health Science domain. Hence, this research presents the development of ontology for the Medical and Health Science domain in the Quran and implementation of ontology-based search method to answer related queries in the Quran.

Table 2: Summary of Ontology Research for Quran

\begin{tabular}{|c|c|c|c|}
\hline References & $\begin{array}{c}\text { Domain/ Cov- } \\
\text { erage Area }\end{array}$ & $\begin{array}{l}\text { Verification } \\
\text { Method Used }\end{array}$ & $\begin{array}{c}\text { Underlying } \\
\text { Format and } \\
\text { Technology } \\
\text { Used }\end{array}$ \\
\hline [21] & "Pray" & $\begin{array}{l}\text { Domain Ex- } \\
\text { perts }\end{array}$ & OWL \\
\hline [22] & "Pray" & $\begin{array}{l}\text { Domain Ex- } \\
\text { perts }\end{array}$ & OWL \\
\hline [23] & "Time Noun" & N/A & OWL \\
\hline [24] & $\begin{array}{l}\text { "Women Noun } \\
\text { and Verbs" }\end{array}$ & N/A & OWL \\
\hline [25] & $\begin{array}{l}\text { "Faith and } \\
\text { Deeds" }\end{array}$ & $\begin{array}{l}\text { Domain Ex- } \\
\text { perts }\end{array}$ & OWL, protégé \\
\hline [2] & "Animals" & N/A & OWL, protégé \\
\hline [26] & $\begin{array}{l}\text { "salat, zakat, } \\
\text { sin, reward" }\end{array}$ & N/A & OWL \\
\hline [27] & "Pronouns" & Ibn Kathir & XML \\
\hline [28] & "nature" & $\begin{array}{l}\text { Domain Ex- } \\
\text { perts }\end{array}$ & OWL \\
\hline [29] & $\begin{array}{l}\text { "Human social } \\
\text { relations" }\end{array}$ & $\begin{array}{l}\text { Tafsir al- } \\
\text { Jalalayn }\end{array}$ & OWL, protégé \\
\hline [30] & $\begin{array}{l}\text { "Juz Amma } \\
\text { (Juz 30)" }\end{array}$ & $\begin{array}{l}\text { Domain Ex- } \\
\text { perts }\end{array}$ & OWL, protégé \\
\hline
\end{tabular}

Furthermore, most existing semantic search tools used only a unique source or part of existing Quran ontologies and that affected the accuracies of the retrieved results. The study in [31] aims the search tools to have a better accuracy in term of precision and recall when answering a user query. Therefore, this paper presents the development of hybrid search tools that utilized semanticbased searching by using ontology and keyword-based search.

\section{Methodology}

This research aims to develop hybrid semantic-based and keyword-based search tool to retrieve the Medical and Health Science related verses from the Quran. In order to address the identified problem, and setting out how this research goal achieved, this research involved two major parts:

1. The first part is concerned with the development of domain ontology for Medical and Health Science domain in the Quran. This ontology is called as QuranMed ontology. 
2. The second part is concerned with the development of hybrid search tool to get an accurate answer from user queries.

Initially, Al-Quran is a root of all the classes (themes) and it is described by subclasses of (Divisions), (Chapters) and Verses. AlQuran knowledge is a collection of division, chapter and verses, whereby the verse is a subclass for chapter, and chapter is a subclass for division [10]. The proposed ontology-based approach for knowledge retrieval in the Quran will be discussed in the following sections.

\subsection{Quranmed Ontology Development}

Ontology modelling is a complex task. Since the 1990s, researchers have proposed several methodologies and methods for ontology development. There is no method that is considered the right one to implement [8]. However, these fundamental rules of ontology design must be followed which are:

- There are many ways of modeling a domain, and the best solution always depends on what the ontology developers have in mind and the extensions that they anticipate.

- Ontology development is necessarily an iterative process.

- Concepts in the ontology should be close to real objects (physical or logical) and relationships in the domain of interest. These concepts should reflect the model as in the real world.

The Ontology Development 101 method that was proposed by [32] has been chosen as the basis and guidance for this research paper's ontology modelling. This method consists of five phases which are specification, integration, conceptualizations, implementation and evaluation.

The QuranMed ontology cover Al-Quran Juz, Chapter, Verses and English Translation based on Sahih International. As shown in Figure 1, the Medical and Health Science theme concepts are extracted based on Malaysian Research and Development Classification System 5th edition by Ministry of Science, Technology and Innovation (MOSTI) which is a specialized agency of research and development activities in Malaysia. Additionally, the QuranMed also has added the linking between the Medical and Health Science concept and DBpedia as shown in Figure 2, the largest web open data [33], where the concept is covered. This linkage helps user to understand the meaning of the terminology and description thoroughly.

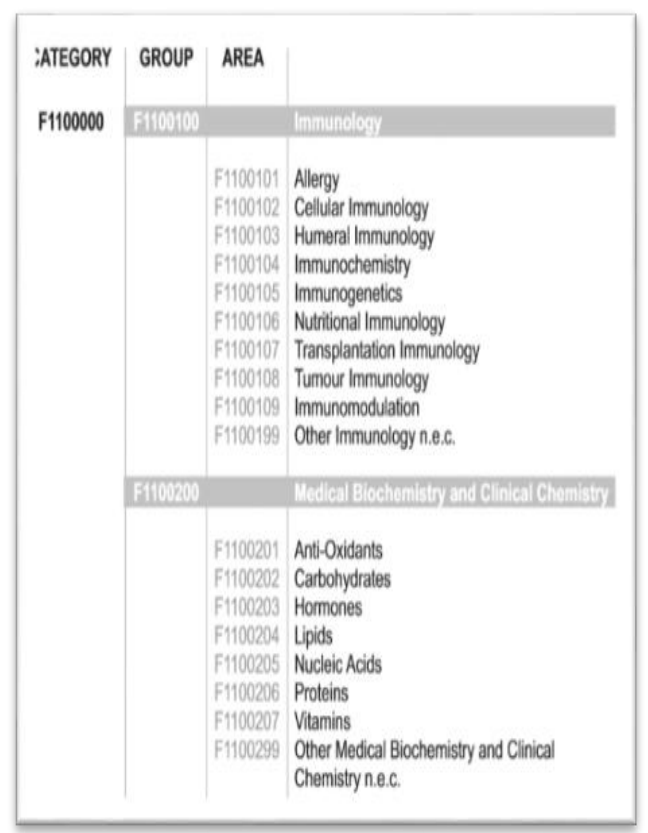

Fig 1: Medical and Health Science Concepts Classification.

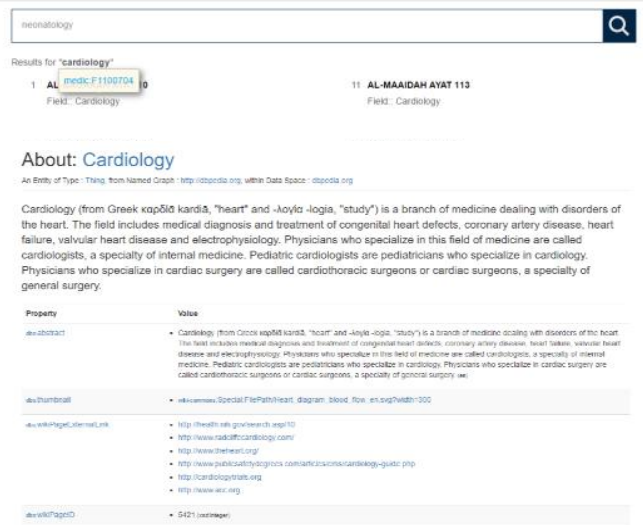

Fig 2: Medical and Health Science concept match with DBpedia

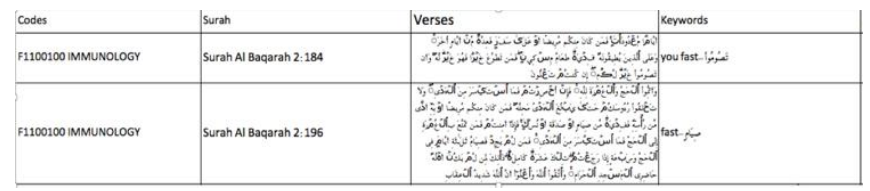

Fig 3: QuranMed Instances dataset.

The instances for QuranMed, where the datasets were prepared and endorsed by the Quran experts from Fakulti Pengajian Quran Sunnah at Universiti Sains Islam Malaysia. These instances describe the relationship between Medical and Health Science field area and Al-Quran verses. Additionally, it also describes the important keyword to enhance searching functionality. It covers all verses in the Quran. These instances were prepared in spreadsheet format as shown in Figure 3 and then were imported by using Java tools. There are 692 total unique instances which have been imported into the QuranMed concepts.

Protégé is used to create the ontology because it is well maintained and contains a number of useful plugins that we can add to facilitate reasoning tasks as well as visualizing the model using diagrams and matrices. Figure 4 shows some statistics of the ontology.

$\begin{array}{ll}\text { Metrics } & \\ \text { Axiom } & 56456 \\ \text { Logical axiom count } & 47888 \\ \text { Declaration axioms count } & 1498 \\ \text { Class count } & 445 \\ \text { Object property count } & 5 \\ \text { Data property count } & 12 \\ \text { Individual count } & 7416 \\ \text { DL expressivity } & \text { ALCOI(D) }\end{array}$

Fig. 4: Ontology Metrics Statistics.

\subsection{Searching Scenario}

The main features of the searching are to allow shortened forms of terms, synonyms and variety approach of searching. In this demonstration, five scenarios are illustrated to show how the system works.

Scenario 1 - Information Retrieval based on a medical field search In this scenario, a user wants to find any verses that are related to medical and health science domain field keyword such as the "Cardiology". The query result can be retrieved with the keyword "cardiology" or by querying the exact verse search that related to it, such as the example here:

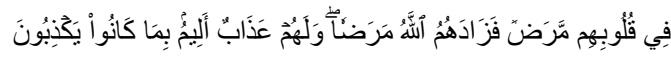

Figure 5 shows how the relationship can be represented between these two words which have been defined using the relations of "hasField" and "hasAyatUthmani" 


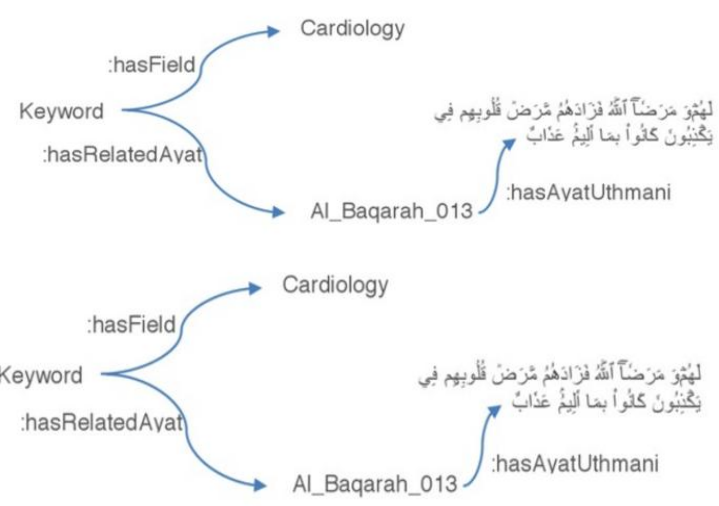

Fig. 5: Relationship of "hasfield" and "hasAyatUthmani"

Scenario 2 - Information Retrieval based Translation search. In this scenario, a user wants to find any verses that are related to medical and health science domain field keyword, such as "There is a disease in their hearts". The query result can be retrieved with the following keyword and match with related field if match.

Figure 6 shows how the relationship can be represented between these two words which have been defined using the relations of "hasField" and "hasTranslation".

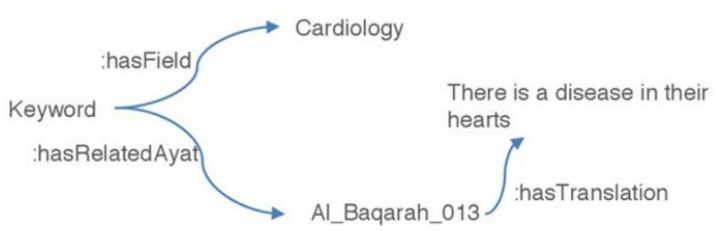

Fig. 6: Relationship of "hasField" and "hasTranslation"

Scenario 3 - Information Retrieval based general keyword search. In this scenario, a user wants to find any verses that are related to medical and health science domain field keyword such as "fool". The query result can be retrieved with the following keyword and match with related field if match. Figure 7 shows how the relationship can be represented between these two words which have been defined using the relations of "hasField" and "hasKeyword".

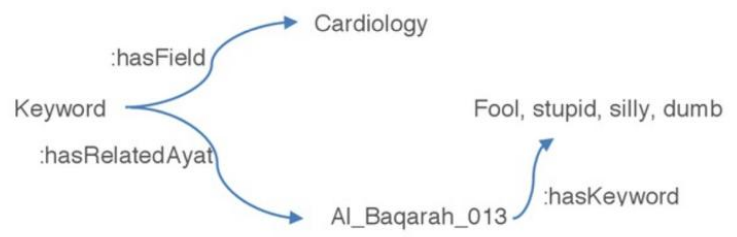

Fig. 7: Relationship of "hasField" and "hasKeyword"

Scenario 4 - Information Retrieval based to see detail description open data in Dbepedia. In this scenario, a user wants to find any verses that are related to medical and health science domain field keyword such as "Al-Baqarah Ayat 10". The query result can be retrieved with the following keyword and match with related field if match.

Figure 8 shows how the relationship can be represented between these two words which have been defined using the relations of "sameAs" and "hasLabel".

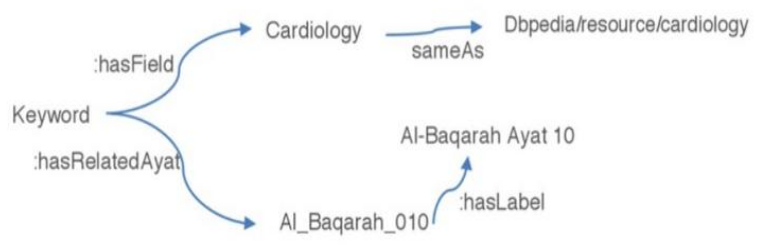

Fig. 8: Relationship of "hasLabel" and "sameAs"

\subsection{Quranmed Hybrid Search Tool}

The hybrid search tool allows non-technical users to use the ontology without writing SPARQL queries, it will parse and analyze the user query regardless the input in Arabic and build SPARQL queries using the ontology concepts and properties. This search tool is called as hybrid because of the searching mechanism that utilized concept search inside ontology and keyword search to match query requested by user if no matching concept found. Figure 9 describes the different steps of the search algorithm.

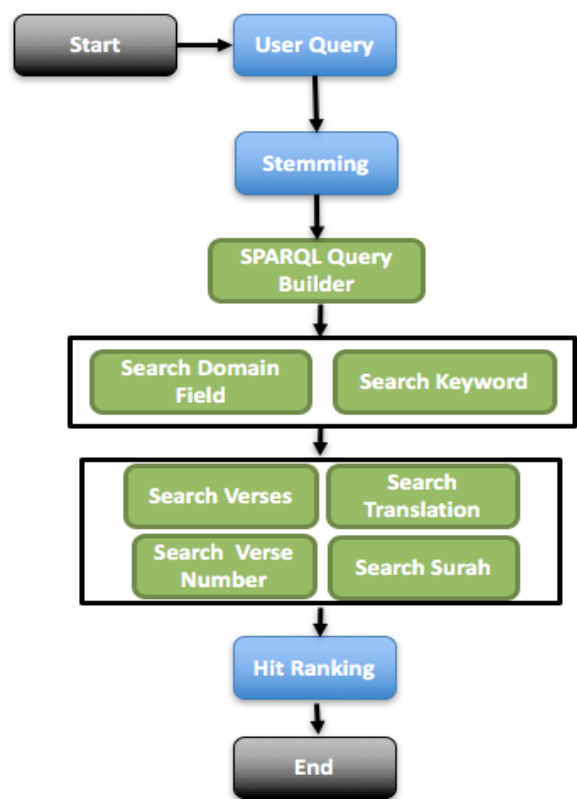

Fig. 9: Hybrid Search Algorithm.

User Query: In this step, user query will be parsed to query processing. The query can be anything including Al-Quran verse, translation, medical and health science keyword, and Al-Quran surah and verse number.

Stop words removal: This search tool implements English stop words removal that removes common stop words such as he, is, at, which, and onto to support exact phrase search. The list of stop words is based on http://www.ranks.nl/ Stop words List.

SPARQL Query Builder: The SPARQL Query Builder was executed in two phases. The first phase will execute searching based on:

- Search Domain Field: Search Al-Quran based on Medical and Health Science concept, such as cardiology, audiology, allergy and immunology.

- Search Keyword: Search the keyword of any random keywords that may relate to Medical and Health Science field such as bones, milk, embryos and intoxicants.

If any of the queries did not match the above searching area, the second phase concept match searching will be executed. This kind of searching will be executed by assuming these criteria will be used by user for searching:

- Search verses: Search Al-Quran verses in Arabic that matches with keyword query. The searching function enables the user who knows the verse, but did not know other related information such surah name or translation

- Search translation: Search Al-Quran translation, the results will be sorted descending from the highest number of match keywords in a single sentence translation.

- Search Surah: Search Surah based on Surah Name for example "Al-Baqarah"

- Search verses number: Search based on the verse number for example "Al-Baqarah Ayat 10" 
- Hit Ranking: The result of searching will be sorted based on hit ranking, where the first phase results will display first based on concept search, followed by keyword search. If no results from the first phase, the second phase searching result will be displayed. The results will be sorted based on the number of hits matched from a user query.

\section{Results and Discussion}

The QuranMed ontology has been validated by Al-Quran and Hadith experts. The expert team is led by Associate Professor Dr. Adnan bin Mohamed Yusoff, whom is a researcher and also the Dean of Fakulty of Quranic and Sunnah, Universiti Sains Islam Malaysia (USIM). The team of experts consists of 12 other researchers whom are the experts in Al-Quran and Hadith domain. The process gathering requirement from expert from initial ontology development, dataset spreadsheet format that was adopted inside QuranMed ontology and evaluation stage was documented in the ontology requirement specification, as shown in the Appendix section.

The QuranMed search tool is tested by using a pre-defined test case. Test case in used in this research to test functionalities and to trace any changes occurs [31]. The test case that is prepared for this method is basically aimed to test the accuracy of searching method. The results of accuracy were based on precision and recall [34]. The dataset that was prepared by the domain experts has been used as a baseline to measure the accuracy of the search tool. For the testing purpose, random query keyword was selected from dataset from experts. The searching approach was made based combination of concept and exact keyword match.

Based on the results from the evaluation, domain field concept search has higher accuracy which is $94.75 \%$ for the recall and $100 \%$ for the precision (see Table 3). This is because semantic search can crawl and retrieve accurately the instances that has a relationship with the related concept. Additionally, reasoner in semantic database, such as Apache Jena, it enriched the triples data which also enrich the relationship between same concepts that shares same instances.

Table 3: Measurement for Searching Result using domain field search

\begin{tabular}{|c|c|c|c|c|c|c|}
\hline QuranMed Field & $\begin{array}{c}\text { Total Verses } \\
\text { Related }\end{array}$ & $\begin{array}{c}\text { Relevance Record } \\
\text { Retrieved }\end{array}$ & $\begin{array}{c}\text { Relevance Record } \\
\text { Not Retrieved }\end{array}$ & $\begin{array}{c}\text { Irrelevance Record } \\
\text { Retrieved }\end{array}$ & Recall (\%) & Precision (\%) \\
\hline Immunology & 2 & 2 & 0 & 0 & 100 & 100 \\
\hline Neonatology & 16 & 14 & 2 & 0 & 88 & 100 \\
\hline Preventive Medicine & 18 & 17 & 1 & 0 & 94 & 100 \\
\hline Proteins & 19 & 18 & 1 & 0 & 95 & 100 \\
\hline Nutrition & 43 & 41 & 2 & 0 & 95 & 100 \\
\hline Cardiology & 41 & 40 & 1 & 0 & 98 & 100 \\
\hline Ophthalmology & 44 & 43 & 1 & 0 & 98 & 100 \\
\hline Total & 225 & 215 & 10 & 0 & 94.75 & 100 \\
\hline
\end{tabular}

Table 4: Measurement for Searching Result using Keyword Search

\begin{tabular}{|c|c|c|c|c|c|}
\hline Keyword & $\begin{array}{c}\text { Relevance Record } \\
\text { Retrieved }\end{array}$ & $\begin{array}{c}\text { Relevance Record } \\
\text { Not Retrieved }\end{array}$ & $\begin{array}{c}\text { Irrelevance Record } \\
\text { Retrieved }\end{array}$ & Precision & Recall \\
\hline Fruit & 53 & 0 & 10 & $100 \%$ & $84 \%$ \\
\hline Water & 8 & 0 & 2 & $100 \%$ & $80 \%$ \\
\hline Intoxicants & 7 & 4 & 0 & $64 \%$ & $100 \%$ \\
\hline Barren & 6 & 1 & 0 & $86 \%$ & $100 \%$ \\
\hline Cattle & 25 & 0 & 19 & $100 \%$ & $57 \%$ \\
\hline a condiment & 4 & 0 & 0 & $100 \%$ & $100 \%$ \\
\hline an ailment of the head & 4 & 0 & 0 & $100 \%$ & $100 \%$ \\
\hline Cry & 2 & 0 & 0 & $100 \%$ & $100 \%$ \\
\hline menstruation & 2 & 0 & 0 & $100 \%$ & $100 \%$ \\
\hline Heart & 40 & 17 & 0 & $70 \%$ & $100 \%$ \\
\hline Female & 10 & 0 & 1 & $100 \%$ & $91 \%$ \\
\hline Bones & 6 & 0 & 3 & $100 \%$ & $67 \%$ \\
\hline Milk & 8 & 0 & 2 & $100 \%$ & $80 \%$ \\
\hline Flesh & 27 & 0 & 1 & $100 \%$ & $96 \%$ \\
\hline Wash & 5 & 0 & 0 & $100 \%$ & $100 \%$ \\
\hline embryos & 3 & 0 & 0 & $100 \%$ & $100 \%$ \\
\hline Skins & 15 & 1 & 0 & $94 \%$ & $100 \%$ \\
\hline wombs & 13 & 0 & 0 & $100 \%$ & $100 \%$ \\
\hline Average & 280 & 27 & 38 & $91 \%$ & $88 \%$ \\
\hline
\end{tabular}

The keyword search test case has $91 \%$ precision and $88 \%$ recall where it is lower than domain field concept search (see Table 4). This is because the keyword searching technique tries to match exact phrase with keywords which leads to lower accuracy when dealing with keyword inside a database that are not stemmed.

\section{Conclusion}

This paper presents the hybrid search approach for retrieving the Medical and Health Science knowledge from the Quran. The search tool encompasses semantic-based (using ontology) and keyword-based technique to answer simple queries from the user. The search tool makes use the QuranMed ontology as a reference and basis to answer user queries. The proposed ontology has been evaluated by domain experts. In addition, the QuranMed search tool has demonstrated high precision and recall when retrieving the Medical and Health Science related queries. For future work, the QuranMed ontology can be used as a reference and basis to answer user queries related to the Medical and Health Science domain in the Quran, to integrate data with other applications or to expand this ontology. Furthermore, the QuranMed search tool can be enhanced by including enhanced query processing technique such as tokenizing, normalization, stemming and synonyms gen- 
erations. It is hoped that in future this search tool can answer complex queries with better accuracy.

\section{Acknowledgement}

This work was supported by Universiti Sains Islam Malaysia [Grant No: PPP/USG-0216/FST/30/15116].

\section{References}

[1] Arbaoui, A., Alginahi, Y. M. \& Menacer, M. (2013). Strategies for collecting electronic resources on the qur'anic researches. Int. J. Quranic Res., 3(4), 57-78.

[2] Ullah Khan, H., Saqlain, S. M., Shoaib, M. \& Sher, M. (2013). Ontology based semantic search in Holy Quran. Int. J. Futur. Comput. Commun., 2(6), 570-575.

[3] Ta'a, A., Abed, Q. A., Ali, B. M. \& Ahmad, M. (2016). Ontologybased approach for knowledge retrieval in Al-Quran Holy Book. Int. J. Comput. Eng. Res. Ontol., 6(3), 8-15.

[4] Alqahtani, M. \& Atwell, E. (2016). Arabic Quranic search too based on ontology. Proceedings of the International Conference on Applications of Natural Language to Information Systems, pp. 478485.

[5] Yauri, A. R., Kadir, R. A., Azman, A. \& Murad, M. A. A. (2013). Quranic verse extraction base on concepts using OWL-DL ontology. Res. J. Appl. Sci. Eng. Technol., 6, (23), 4492-4498.

[6] Mangold, C. (2007). A survey and classification of semantic search approaches. Int. J. Metadata, Semant. Ontol., 2(1), 23.

[7] Kalfoglou, Y. (2007). Using ontologies to support and critique decisions. Eng. Intell. Syst. Electr. Eng. Commun., 15(3), 159-166.

[8] Hakkoum, A. \& Raghay, S. (2016). Semantic Q\&A system on the Qur'an. Arab. J. Sci. Eng., 41(12), 5205-5214.

[9] Beseiso, M., Ahmad, A. R. \& Ismail, R. (2010). A Survey of Arabic language Support in Semantic web. Int. J. Comput. Appl., 9(1), 35-40.

[10] Ta'a, A., Abdullah, M. S., Ali, A. B. M. \& Ahmad, M. (2014) Themes-based classification for Al-Quran knowledge ontology. Proceedings of the IEEE International Conference on Information and Communication Technology Convergence, pp. 89-94.

[11] Shoaib, M., Yasin, M. N., Hikmat Ullah, K., Saeed, M. I. \& Khiyal, M. S. H. (2009). Relational WordNet model for semantic search in Holy Quran. Proceedings of the Int. Conf. Emerg. Technol., pp. 2934.

[12] Atwell, E. et al. (2010). Understanding the Quran: A new grand challenge for computer science and artificial intelligence. Gd. Challenges Comput. Res. Br. Comput. Soc. Work., 1(11), 18291841 .

[13] Alqahtani, M. \& Atwell, E. (2017). Evaluation criteria for computational Quran search. Int. J. Islam. Appl. Comput. Sci. Technol., 5(1), 12-22.

[14] Sudeepthi, G., Anuradha, G. \& Babu, M. (2012). A survey on semantic web search engine. Int. J. Comput. Sci., 9(2), 241-245.

[15] Al-Jarrah, O., Al-Kiswany, S., Al-Gharaibeh, B., Fraiwan, M. \& Khasawneh, H. (2006). A new algorithm for Arabic optical character recognition. Proceedings of the 5th WSEAS Int Conf on Signal Processing Robotics and Automation, pp. 211-224.

[16] Shawar, B. A. (2011). A chatbot as a natural web interface to Arabic web QA. Int. J. Emerg. Technol. Learn., 6(1), 37-43.

[17] Raza, S. A., Rehan, M., Farooq, A., Ahsan, S. M. \& Khan, M. S (2014). An essential framework for concept based evolutionary Quranic search engine. Science International. 26(1), 181-184.

[18] Yauri, A. R., Kadir, R. A. Azman, A. \& Murad, M. A. A. (2013) Ontology semantic approach to extraction of knowledge from Holy Quran. Proceedings of the 5th International Conference on Computer Science and Information Technology, pp. 19-23.

[19] Yunus, M. A., Zainuddin, R. \& Abdullah, N. (2010). Semantic query for Quran documents results. Proceedings of the IEEE Conference on Open Systems, pp. 1-5.

[20] Yahya, Z., Abdullah, M. T., Azman, A. \& Abdul Kadir, R. (2013). Query translation using concepts similarity based on Quran ontology for cross-language information retrieval. J. Comput. Sci., 9(7), 889-897.

[21] Saad, S., Salim, N. \& Zainal, H. (2009). Pattern extraction for islamic concept. Proceedings of the Int. Conf. Electr. Eng. Informatics, pp. 333-337.
[22] Saad, S., Salim, N. \& Zainal, H. (2010). Towards context-sensitive domain of Islamic knowledge ontology extraction. Int. J. Infonomics, 3(1), 197-206.

[23] Al-Yahya, M. \& Al-Khalifa, H. (2010). An ontological model for representing semantic lexicons: An application on time nouns in the Holy Quran. Arab. J. Sci. Eng., (352), 21-35.

[24] Al-Khalifa, H. S., Al-Yahya, M. M., Bahanshal, A. \& Al-Odah, I. (2009). SemQ: A proposed framework for representing semantic opposition in the Holy Quran using semantic web technologies. Proceedings of the Int. Conf. Curr. Trends Inf. Technol., pp. 44-47.

[25] Ali, B. \& Ahmad, M. (2013). Al-Quran themes classification using ontology. Icoci.Cms.Net.My, 74, 383-389.

[26] Yauri, A. R., Kadir, R. A., Azman, A. \& Azmi Murad, M. A (2012). Quranic-based concepts: Verse relations extraction using Manchester OWL syntax. Proceedings of the Int. Conf. Inf. Retr. Knowl. Manag., pp. 317-321.

[27] Muhammad, A. (2012). Annotation of conceptual co-reference and text mining the Qur'an. PhD thesis, University of Leeds.

[28] Sadi, A. B. M. S., Anam, T., Abdirazak, M., Adnan, A. H., Khan, S Z., Rahman, M. M., \& Samara, G. (2016). Applying ontological modeling on quranic 'nature' domain. Proceedings of the 7th International Conference on Information and Communication Systems, pp. 151-155.

[29] Tashtoush, Y. M., Al-Soud, M. R., AbuJazoh, R. M. \& Al-Frehat, M. (2017). The noble quran Arabic ontology: Domain ontological model and evaluation of human and social relations. Proceedings of the 8th International Conference on Information and Communication Systems, pp. 40-45.

[30] Periamalai, N. S. H. A. R., Mustapha, A. \& Alqurneh, A. (2016). An ontology for Juz' Amma based on expert knowledge. Proceedings of the 7 th International Conference on Computer Science and Information Technology, pp. 1-5.

[31] Ou, S., Pekar, V., Orasan, C., Spurk, C. \& Negri, M. (2008). Development and alignment of a domain-specific ontology for question answering. Proceedings of the 6th Ed. Lang. Resour. Eval. Conf., pp. 2221-2228.

[32] Noy, N. F. \& McGuinness, D. L. (2001). Ontology development 101: A guide to creating your first ontology. Stanford Knowl. Syst. Lab., 25, 2001

[33] Auer, S., Bizer, C., Kobilarov, Lehmann, G., Cyganiak, J. R., \& Ives, Z. (2007). DBpedia: A nucleus for a Web of open data. Lecture Notes in Computer Science (including subseries Lecture Notes in Artificial Intelligence and Lecture Notes in Bioinformatics), 4825, 722-735.

[34] Aleksovski, Z., Ten Kate, W., \& Van Harmelen, F. (2008). Using multiple ontologies as background knowledge in ontology matching. Proceedings of the CISWEB Workshop: ESWC Workshop on Collective Semantics, pp. 35-49. 